\title{
ASPECTOS DO NOVO ROMANCE
}

\section{ZILIA MARA SCARPARI SCHMIDT}

O chamado "Nouveau Roman" já não é tão novo quanto seu nome pode nos fazer crer. Entre as duas obras que piocuraram traçar as diretrizes da nova ficção dos anos cinqüenta e sessenta (L'ère du soupçon, de Nathalie Sarraute, 1956 e Pour un Nouveau roman, de Alain Robbe-Grillet, 1963) e as últimas publicações de Jean Ricardou, principal teórico das atuais tendências( $\left.{ }^{(}\right)$, a evolução é sensível. Um exame cauteloso poderia detectar muitas diferenças que separam duas gerações de romancistas que, aliás, jamais apresentaram perfis homogêneos. Limitar-nos-emos, contudo, ao esboço das principais características destas duas gerações e, abandonando em seguida as diferenças, tentaremos mostrar alguns dos procedimentos que poderiam identificá-las.

\section{1 \\ NOVO ROMANCE E NOVISSIMO ROMANCE}

A primeira geração do Novo Romance continua a insurreição contra os mo!des da tradicional ficção balzaquiana. $O$ homem do século XX não pode mais assistir passivamente ao desenvolvimento artificial de uma in:riga sólida, num mundo romanesco estável, coerente e reconfortante. Por outro lado, o novo romance não pode igualmente seguir a trilha da literatura engajada de após-guerra, quando existe a consciência de que a função da arte não é apon'ar para sigrificados já existentes, comunicar um saber apriorístico, mas fundar novos significados, gerar novos sistemas de signos. Trata-se de cultivar um "romance experimental" (num sentido bem diferente do de

1 Suas obras estão relacionadas na bibliografia final. 
Zola), profundamenie maicado pela pesquisa fenomenológica. Aparecem então os traba'hos de Nathalie Sarraute, Michel Butor, Jean Cayrol, Marguerite Duras, Robe:t Pinget, Claude Simon, Claude Ollier, Alain Robbe-Grillet, peecedidos dos de Samuel Beckett. A critica fala de uma "nouvel!e vague" do romance, de "escola de Minuit" (a editora Minuit foi a primeira a acolher os novos romancistas), de "esco.a do olhar", de "romance objeial", de "anti-romance" e, finalmente, de Novo Romance. Esie se caracteriza "giosso modo" pela divisão da unidade diegéticá, por construçōes sofisticadas, pelos excessos da descrição objetal, pela subversão da categoria do Fersonagem e do narrador. Apesar de toda revolução, ainda é possível encontra: uma estrutura rela:ivamente uniłária; em outras palavras, consegue-se ainda "resumir a história" (La Modification, Les Gommes, Le Voyeur, etc.), traçar, embora com dificuldade, o perfil de um Léon Delmont, reconhecer a técnica do ponto-de-vista mais ou menos fixo ou constante (La Jalousie, Les Gommes, Le Voyeur). E o anti-romance ou o romance da anti-representação.

A segunda geração é representada por Jean Ricardou, Philippe Sollers, J. Louis Baudry, Jean Thibaudeau, que se agrupam em torno das edições Seuil e da revisła Tel Quel, donde o nome de "romance telqueliano", que varia entre as designações de "Nouveau Nouveau Roman", "Néo-Nouveau Roman" e - aciescentaríamos - Novíssimo Romance. Embora não pub'icadas pela Sevil, incluímos á as últimas produções de Robbe-Grillet e de Claude Simon $\left({ }^{2}\right)$. Percebe-se, nesta, çeração, a influência dos traba'hos de lingüística estrutural, bem como uma orien ação marxista. E o periodo subversivo e radical do Novo Romance. Philippe Sollers, por exemplo, denuncia "a ideologia positivista do Novo Romance, que oscila entre uma sobrevivência psicologista (e aqui ele se refere ao psicologismo de Nathalie Sarraute e à sua exploração da tésnica da corrente de consciência) e um descricionismo decorativamente es'rutural" $\left({ }^{3}\right)$. Uma diegese completamente plural incita a "guerrä" de narrativas. E vã a procura de uma narrativa unitária. Do estado de agressão à unidade empreendida pela primeira ge:ação, passa-se as es:ado de uma unidade impossível.

2 Consultar biblicgrafia final. Deste modo, toda citação de textos literórios será acompanhada simplesmente do rúmero da página em que se encontra.

3 Citado por BOTHOREL, Nico!s et alii. Les nouveaux romanciers. Paris, Bordas, 1976, p. 16. Traduzimos us citaçōes tzóricas a $\mathrm{f}: \mathrm{m}$ de uniformizar o trabalho. O texto literário tarmbém foi por nós traduzido. Esta, porém, é acompanhado de sua versão original em notas de rodapé. 
A narrativa é violeniada, a categoria do personagem é simplesmente abolida. O anti-romance ou anti-representação evolui para o autoromance, auto-representação ou auto-reflexão. Propõe-se um romance que se escreva sozinho e não mais, por exemplo, na perspectiva. de um personagem ciumento (La Jalousie), de um tipo obsessivo (Le Voyeur) ou pela consciência de um burguês insatisfeito (La Modification). Ao neo-iealismo fenomenológico Ricardou opõe o "escrituralismo": o tema do livro será sempre a sua própria composição, o romance não é mais a escritura de uma aventura, mas a "aventura de uma escritura" ${ }^{\left({ }^{4}\right)}$. A escriłura deve ser explorada como um espaço particular. A fábula não preexistirá à intriga. A própría linguagem será simultaneamente material romanesco e narração que, agora· indissociáveis, vão refletir um fenômeno de auto-fecundação do texto.

O Novíssimo Romance insiste na noção de texto como uma prática semiótica, um processo de produção de sentido, situado num espaço de confluência de muiłos textos que serão absorvidos, refutados ou transformados. $\left(^{5}\right)$ E uma escritura-leitura da qual autor e leitor são entidades participantes. É nesta mesma perspectiva que o romance se quer um espelho de seus próprios princípios narrativos, diante do qual o leitor é coagido a encontrar, sozinho, as regras do jogo e, deste modo, impelido a participar da produção do texto, numa atividade altamente consciente.

\section{II \\ REIFICAÇÃO e CONTRA-REIFICAÇÃo}

\section{A morte do personagem e a flutuação do ponto-de-vis'a.}

Os personagens do Novo Romance caracterizam o mundo reificado em que vivemos, a época atual que, segundo R'obbe-Grillet, é antes a do número de matrícula. $\left.{ }^{(}\right)$Temos o que humoristicamente se chamou de "robots-grillés", devido ao tratamento sádico a que são submetidos os autômatos grilletiânos. Na moderna sociedade capitalista a biografia, a psicologia do indivídus perdem a importância.

4 RICARDOU, Jean. Problèmes du Nouveau Roman. Paris, Sevil, 1967. p. 111. 380 p.

5 Cf. KRISTEVA, J. Semiotikè; recherches pour une sémanalyse. Paris, Seuil, 1969.

6 ROBbE-GRILlet, Alain. Pour un nouveau roman. Paris, Gallimard, 1963. p. 33. 
E!e se torna um episódio acidental na História e, conseqüentemente, na "história" do romance. Assim, em La Bataille de Pharsale (Claude Simon), o personagem é reduzido à léra $\mathrm{O}$ - que também pode ser entendida como ze:o. E por 0 se designa as mesmo tempo o sbservador (o tio), o objetc observado (o sobrinho), um homem a uma mulher. Em La Maison de Rendez-Vous (Robbe-Grillet), l.ady Ava, Eva Bergmann e Jacqueline são a mesma pessoa. Os nomes não identificam ninguém e, lembrando curiosamente os do mundo do cinema (Ava, Bergmann, Kim, Lau:en), parecem querer salientar seu próprio caráter ficcional e meniroso, num espaço onde tudo é teoricamente possivel, porque ai a realidade é uma ilusão e o caráter lúdico uma constante. Daí os nomes obedece:em, muitas vezes, a um jogo fônico gratuito. Tal é o caso das "variantes livres" Matadier, Mon'oret, Montaret, Montalet (Dans le labyrin he, Robbe-Grillet), Lauren, Laureen, Loraine (La Maison de Rendez-vous), eic.

Os personagens são, pois, submetidos a uma série de variantes e de duplos. A mu!:idão ext:avagante de heroínas e de heróis estereotipados da paraliterafu:a que invadem Proje' pour une révoluion a New York (Robbe-Grillet) desnorteiam o lei:o:, destruinds qualquer tentativa de identificăção.

Enfim. o personagem é reduzido à noção de pessoa gramatical.

Não podemos deixar de lembrar aqui a lição de Emile Benveniste("). O pronome eu é desprovido de toda referência material, é um signo vazio, sem entidade lexical, e só existe na situoção de discurso. O fronome de segunda pessoa tem as mesmas características, pois se define paralelamente ao eu. "Desp:ovidos de referência ma'erial (...), nada asseverando, e'es não estão submetidos à condição de verdade $\varepsilon$ escapam a toda denegação"( ${ }^{(5)}$. Por esta razão, talvez, é que o Novo Romance faz destes pronomes um uso abusivo. Quanto à terceira pessoa, ela é, na realidade, uma não-pessoa porque remete a una situaçăo objetiva, extradiscursiva. Trata-se de um pu:o substituto e, como tal, permile no Novo Romance as mais variadas subs'iłuiçōes e metamorfoses: ele pode referir-se a todos os elementos masculinos da ficção; ela pode referir-se a todos os elementos femininos. Isso

7 BENVENISTE, E. Problèmes de lingui.tique gináale. Paris, Gallimard, 1966 356 ?.

8 lbid. p. 254. 
se não considerarmos que o Novo Romance confunde os gêneros (o caso de $O$, por exemplo). E se a terceira pessoa substitui todo nome próprio ou todo substantivo comum, ela acaba, num caso limite, por substituir o pronome eu. Dal o nomadismo dos pronomes, a livre circulação do eu ao ele e vice-versa.

\section{Vejamos alguns exemplos de Proje:o para uma revolução em Nova lorque:}

O homem é muito mais forte que essa, frágil adolescente cuja resistência é inútil, divertida e irrisória. Ele soltou-lhe, os lábios, num gesto rápido, para agarrar os dois pulsos (...) Quando pareceu morta, sol.ei-a do meu braço. $\left({ }^{\circ}\right)$

Eis uma livre substituição do homem por ele, depois por eu. A cena se refere mais propriamente a uma, violência deliberada contra o processo de enunciação do que à violação da jovem Laura.

O exemplo seguinte ilustra a passagem do eu ao ele, depois ao personagem:

Não posso dizer o que fizeram em seguida, porque retomei imediatamente meu caminho (...) Entretanto ele não deixa de continuar seu caminho, até mesmo apressando o passo (...) Lá embaixo, como se pensasse estar dali em diante fora de vista, o personagem suspeito se põe a descer a invisível escada de uma boca de metrô...( $\left.{ }^{(1)}\right)$

Outras vezes, mesmo sem mudança de pronome, a identidade do narrador varia. E o que acontece na passagem de Projeto em que JR

9 "L'homme est beaucoup plus fort que cette frêle adolescente dont la résistance est sans issue, amusante et dérisoire. Il lui a d'un geste prompt lâché lés lèvres pour saisir les deux poignets (...) Quand elle a semblé morte, i'ai relâché mōn étreinte". ROBBE-GRILLET, A. Projef pour une révolution à New York. Paris, Minuit 1970. p. 18-17. Os grifos na traduçāo são nossos.

10 "Je ne peux dire ce qu'ils ont fait ensuite, car je me suis immédiatement remis en marche (...) Cependant il ne continue pas moins sa route, pressant même le pas. (...) Là-bas, comme s'il pensait être désormais hors de vue, le personnage suspect se met à descendre l'invisible escalier d'une bouche de métro..." Projet... p. 22-23. 
é enviada à casa de Laura pela agência de informações da qual o personagem-narrador é membro quando, subitamente, JR se apropria do nós do narrádor, designando-se a si e a Laura por este pronome:

Nós enviamos então JR, exuberante moça de raça branca (...) Depois nós ficamos quietas as duas durante algum tempo que me pareceu bastante longo.(11)

A partir dai, escorrega-se de JR ao narrador e vice-versa, tornando-se cada vez mais difícil identificar o sujeito da enunciação. $O$ posto do narrador está sempre disponivel para ser livremente preenchido por qualquer pe:sonagem, extra ou intradiegético, pela voz de uma fita gravada e, afé mesmo, pela do narador de um romance policial "em abismo"...

O narrador está poitanto simultaneamente no exterior e no interior de sua própiia nairação, uma narração que tem uma autonomia que the escapa.

Personagem, narrador e narratário são reduzidos a palavras, a atores gramaticais, confundindo-se tanto os niveis do enunciado e da enunciação, como o universo literário e o extraliterário. Com esta dessacralização do processo da escrifura a ficção moderna proclama um vertiginoso gênero fantástico:

Parecem ( $M$, o vampiro e o doutor Morgan) ince:tos, fatigados. $M$ descola um instante a máscara, num gesto maquinal, para teniar apagar com a palma da mão as rugas de sua verdadeira face, por baixo; e Morgan, que levanta agora os olhos da papelada acumulada na mesa, reconhece com estupefáção os traços do narrador. Sem hesitar, venda-me descobrir... Corte. $\left({ }^{12}\right)$

A primeira fase do Novo Romance explora sobretudo o tipo narrador fixo-narração flutuante. E o caso de la Jalousie, onde tudo é

11 "Nous avons donc envoyé JR, somptueuse fille de race blanche (...) Puis nous nous sommes tues, toutes les deux, pendant un temps qui $m^{\prime a}$ paru assez long." Projot... p. 57-58.

12 "lls ont l'air incertains, fatigués. $M$. décolle un instant son masque, d'un geste machinal pour tenter d'effacer avec le plat de sa main les plis de son vrai visage, parcessous; et Morgan, qui lève alors les yeux des paperasses accumulées sur la table, reconnait avec stupéfaction les traits du nerrafeur. Sans hésiter, me voyant découvert... Coupure". Proint... p. 213-214. 
percebido por um único observador cujos ciúmes desencadeiam uma série de versões con'raditórias de um mesmo fato. Na segunda fase, ao contrário, toda tentativa de apropriação da narrativa por quem quer que seja se torna precária. E uma linguagem que se fala e se escreve sozinha.

Essa recusa de todo e qualquer tipo de propitiedade e de apropriação se reflete também no aspecto intertextual do Novo Romarice.

\section{Intertextualidade.}

Enquanto os autores tradicionais procuram a própria originalidade, uma ceita "diferença", os novos romancistas não se interessam pelos aspectos individuais da obra: enfatizam, ao contrário, o caráter coletivo da literatura. "O texto pertence a todos e a ninguém..."(13)

Daí a insistência na. noção de uma intertextualidade consciente.

Existe um processo de circulação nas obras de um mesmo autor. Em La Maison de Rendez-Vous, são numerosas as alusões às obras precedentes de Robbe-Grillet: o mito de Edipo, o nome Marchat, peixes podres (Les Gommes), cordinhas, barbantes, o nome Jacqueline, o caçador na bicicleta, os círculos, etc. (Le Voyeur), o cenário vegetal, barulhos de insetos, processos de "gommage" (La Jalousie), o pacote misterioso, escadarias e corredores, cortinas de veludo (Dans le labyrinthe). Projeto (p. 34) repete exatamente uma frase de Dans le Labyrinthe (p. 9): "Dehors il pleut. Dehors on marche sous la pluie en courbant le tête".

O mais interessante, porém, são as inúmeras referências a outros textos de outros autores. Não se trata de citações puramente ornamentôis, mas de inserções funcionais. Em La mise en scène (Claude Ollier), o ciúme que momentaneamente Lassale sente por Yamina não é explicitado no texto, mas sugerido pela estilização de um trecho descritivo de La Jalousie. A passagem inserida, que à primeira leitura

13 SOLLERS, Citado por BOTHOREL... P. 94.

14 O exemplo é citado por RICARDOU, Jean. Pour une théorie du Nouveau Roman. Paris, Seuil, 1971, p. 186. La miso en scène: "Maintenant l'ombre du noyer s'étend à mi-chemin de la tente et du mur de pierres séches qui marque l'extrémité du champ."

La Jalousie: "Maintenant l'ombre du pilier - le pilier qui soutient l'angle sud. ouest du toit - divise en deux partes égales I'angle correspondant de la terrasse." 
parece fora de contex:o, lembra um fragmento da célebre descrição da sombra projetada pelos pi'ares da casa em frente ao bananal. Entretanto é justamente a evocação de La Jaulousie que lembra indiretamente os ciúmes. $\left({ }^{1+}\right)$ Pensamos tra:a:-se de um caso de "ordination métaphorique", isto é, "duas células bastante distantes (elas perten cem a texios de signatários diferentes) se "telescopam" a partir de seu ponto comum" ( $\left.{ }^{15}\right)$ ou seja, nos dois textos, o processo de "sinonimia estrutural". Em La Bataille de Pharsale (Claude Simon), a vigésima primeira estrofe do Cimetière Marin de Valéry constitui uma espécie de epigrafe geradora do romance. Embora os assunios do poema e do romance não se identifiquem, todos os termos do Cimetière Marin são retomados e variados como diretrizes temáticas e sêmicas.

O Novo Romance utiliza, também, de maneira sistemática e com fins parodísticos, os temas e procedimentos estereotipados da paraliteratura, sobretudo dos romances eróicos, po'iciais, de espionagem, de terro:. Mas, a intertextualidade não remete só ao código literário cu artístico. No Novo Romance os referentes exiernos podem ser iclentificados e então reconhecemos toda uma mitologia urbana: o niito de Teseu no labirinto das cidades grandes, dos metrôs e dos imóveis, a descida aos infernos do crime, da violência e das diogas, a purificação pelos incêndios, todas as formas de publicidade, todas as marifestações da literatura popular, enfim, uma multidão de signos cujo conjunto constitui a mitologia da civilização contemporânea.

E entreanto nos referentes internos que a nova literatura se centra. É a própria aventura escritural, na sua errância, na sua busca, na sua pesquisa que i'ustra a moderna versão do mito de Teseu.

\section{A contra-reificação na descriçāo objetal.}

\section{A conira?reificaçāo na descriçāo objeałl.}

O que mais chocou nos novos romancistas foi a verdadeira invasão de objetos, descritos com uma rigorosa precisão geoméirica. Mal compreendido a princípio, Robbe-Grillet foi criticado por propor uma literatura objetal, desumanizada. Na verdade, segundo Goldmann $\left({ }^{16}\right)$,

- Novo Romance, com seu universo objetal, é o reflexo de uma sociedade capitalista que assiste ao desaparecimen o progressivo do in-

15 RICARDOU, J. Nouveaux problèmes du roman. Paris, Seuil. 1978. p. 130.

16 GOLDMANN, Lucien. A sociologia do romance. Rio, Paz e Terra, 1976. p. 171-195. 
divíduo como realidade essencial, quer como indivíduo, quer como universo autônomo, com sua estrutura própria, que só admite ao homem exprimir-se ainda algumas vezes e dificilmente. Goldmann mostra como os mecanismos de auto-regulagem que caracterizam este sistema (leis da oferta e da procura, crises que corrigem periodicamente os desequilibrios) aparecem em Les Gommes.

Uma organização clandestina, antigovernamental decidiu matar um homem todos os dias. Acontece que a, última vítima escolhida é apenas ferida. Um detetive é destacado para investigar o crime que, na realidade, não ocorreu. Entretanto, pelo caráter fatal e mecânico do processo, o detetive matará involuntariamente a suposta vítima, converida assim em vítima real, o que permitirá prosseguir a investigação agora de um assassinato efetivo, sem que ninguém se tenha dado conta do erro cometido e sem perturbar o trabalho do grupo terrorista que fará matar outro homem no dia seguinte. $O$ romance ilustra, portanto, um sistema de auto-regulagem que é uma espécie de "gommage", um mecanismo que apaga, os mal-sucedidos, todo traçc de desordem e toda realidade individual. A conseqüência deste estado de coisas na sociedade se reflete na impotência total do indivíduo, na passividade das massas. Diante dos crimes do mundo somos todos olheiros, como parece nos fazer ver le Voyeur.

O Novo Romance, ao contrário do que se possa pensar, não é uma literatura de desumanização, pois a impessoalidade total é evidentemente uma quimera, conforme reconhece Robbe-Grillet. $O$ que - autor condena é o humanismo trágico, o qual seria a comunicação estática ou a ruptura trágica entre o homem e o mundo( $\left.{ }^{17}\right)$, atitudes representadas pela literatura de Sartre e de Camus. O novo romancista propõe então a distinção: as coisas são as coisas e o homem é o homem. "O homem olha o mundo e o mundo não lhe devolve o olhar" $\left.{ }^{\prime 18}\right)$. Não deve existir entre os dois nem uma visão íntima, um pacto metafísico, nem um distanciamento radical. Ambos devem coabitar harmonicamente, tendo-se uma visão clara de uma coisa e outra. Esta espécie de "purificação do contágio" visa a restabelecer a liberdade do homem na consciência. lúcida de sua situação exata. 0 objeto não remete a nada e a ninguém. "Il se contente d'être là". Nada pertence a ninguém e é dessa espécie de "desapropriação" que surge a verdadeira independência do homem.

17 ROBBE-GRILlet, Pour un Nouveau Roman... p. 55-84.

18 Ibid. p. 65. 
Assim, embora pareça pa:adoxal, uma das formas da contra-reificação reside justamente na descrição objetal do Novo-Romance.

Sob outro prisma, a descrição não tem mais por finalidade informar um saber positivo; o que faz é mostrar como o homem percebe e conhece o mundo. Dai a abordagem fenomenológica do real. As diretrizes formais, escriturais substifuem o sentido apriorístico ou final das ditas descriçōes "realistas". Existe agora a introdução sistemática da dúvida, da ambigüidade na percepção e na. descrição. Daí o interesse pelo ponto-de-vista complexo, pelas anulações, pelas autocorreções, pela introdução das hipóteses, dos modalizantes que invadem o espaço texı́ual. Abundam os "peut-être", "sans doute", "probablement". A descrição não pode relatar com segurança o mundo real; deste modo, ela se instaura primordia!mente como um trabaIno de escritura, como um dos ge:adores de ficção.

\section{III}

\section{OS GERADORES DE FICÇÃO}

\section{A descriçāo "antimimética": "mise en vie" a "mise en image".}

E restringida a capacidade da análise descritiva de um objeto na escolha hierárquica dos detalhes que, paradoxalmente, irrompe a dimensão referencial da desciç̧ão naturalista. Para os novos roman cistas, entretanto, a obediência a essa hierarquia, que restringe as capacidades da análise descritiva de um obje:o, reduz o realismo a uma simples ilusão referencial.

Na verdade, um objeto faz parte de um contexto; determinar sua sifuação do ponto-de-visła espacial e temporal significa fazer surgir riovos objeto. Estes objełos secundários, uma vez descritos, ocuparão - mesmo plano superior do objeto principal e, por conseguinte, acavam tornando-se objetos piincipais. Ao nível da linha descritiva, não há jamais objetos secundários, não há hierarquia de objetos. A descrição do Novo Romance é anti-autoritária. Tudo está no mesmo pla.no. Daí o processo descritivo vertiginoso. Na ânsia de apreender o cbjeto na sua simultaneidade, a descrição se to:na digressiva, parentética, proliferante e, por conseguinte, antimimética $\left({ }^{19}\right)$. Enfim, perde-se de vista o objeto, sempre substituído por uma de suas partes.

$19 \mathrm{Em}$ oposiçäo à descriçäo clátsica que chamamos de mimética. No fundo, ensretanto, todas as manifestaçōes da arte prevém de um mesmo impulso: imitar a naturezo. 
Sem querer discutir o conceito des mímesis, os novos romancistas sublinham a antinomia entre a dimensão referencial e a dimensão da escritura. E nesta guerra, a descrição concilia dois papéis contraditórios: 0 da unificação e o da fragmentação. E o que mostra Ricardou $\left({ }^{20}\right)$.

A descrição desempenha seu papel unificador no plano da dimensáo referencial do objeto descrito: enquanto um todo feito de partes simultâneas, 0 objeto descrito assegura a coerência semântica da descrição. No plano da dimensão literal, ou seja, na linha de escritura, - objeto "explode", a descrição se fragmenta. Assim, quanto mais um objeto é descrito, menos ele é "visto".

A imobilidade inicial dos objetos e das cenas se substitui, por conseguinte, uma descrição dinâmica que se transforma em fábula, em matéria da narração, pois só a ordem que a descrição escolhe para apresentar as diversas partes de um todo, por exemplo, já basta para estabelecer uma intriga.

Uma das formas de realização da nova descrição geradora é a animizaçāo do objeto ou "mise en vie" $\left.{ }^{21}\right)$. Em L'observatoire de Cannes (Ricardou), é um cartão postal que se anima. Em Tryptique (Claude Simon) é um cartaz de circo que se transforma no próprio circo. Em Dans le labyyrinthe, a descrição de um quadro representando uma taberna gera uma cena "real". Nas primeiras páginas de Projeto, o desenho formado pe'a nodosidade de uma porta se metamorfoseia gradativamente e o desenho se anima.

Isto é explicado dentro do espaço escritural. Cada detalhe, ao ser abordado paríicularmente, é dissociado do seu conjunto que se fragmenta, adquirindo autonomia e escapando ao controle da já longínqua situação inicial. Cada detalhe se dota então de "vida" própria. Quanto mais longa a sequiência da descrição, tanto mais admissivel será a animação do objeto, pois que estará mais distante (uma disiância marcada pelas linhas) da situação inicial, onde o fenômeno poderia parecer inconcebível.

Da mesma. forma que temos a animação de um objeto ou de uma cena fornecidos por uma pintura, uma fotografia ou uma es-

20 RICARDOU, J. Nouveaux problèmes... p. 30-31.

21 Em oposição ao que Ricardou chama de "mise en image" e em analogia ao procedimento da "mise en abyme". 
cultura, através de um processo de "liberação" da imagem, temos o processo inve:so, isto é, a "cap.ura" do real pela imagem, que Ricardou chama de "mise en image"(22). Em Projeio, a descrição de uma bárbara experiência de inseminação artificial se revela, no final, como a capa de um romance popular. Tryptique nos fornece a descrição natuialista de uma cena de vislação que se imobiliza num cartaz de cinerra. Nesta mesma obrá, temos o exemplo de uma representação captada por ou:ra: um filme se metamorfoseia em pincura.

A ficção não é, pois, uma história apriorística que a narração vâi atualiza:. O que temos é uma história gerada por uma descrição, onde não se separam os planos do "real" e do "ilusório", do "verdadeiro" e do "falso". Na medida em que todos os planos são efeitos de palavras, todos apresentam um mesmo estatuto, todos são identicamente fiç̧ão.

Most:ando seu próprio fazer-se, o Novo Romance ataca toda e qualquer noção de verossimilhança, reconhecendo explicitamente seu caráter ficcional. Daí muitas vezes a desmistificação do processo descritivo:

Sobre o mármore pre:o e opaco, a pequena chave se delineia em linhas claras com a nitidez de um sistema de lições de coisas. Sua argola chata, perfeitamente circular, está situada a apenas alguns centímetros da base hexagonal do castiçal, etc. cujo corpo emoldurado (caneluras, moldu:as redondas na base, cavelos, ducinas, molduras semicirculares, etc.) supo:ta... . etc. $\left({ }^{23}\right)$.

O narrador, como que cansado de seus próprios exercícios descritivos, decide proceder a um "esquema de lições de coisas", isto $\dot{\epsilon}$, decide mostrar-nos os mecanismos de sua téznica descritiva. Para tanto, um tema é proposto (o castiçal de cobre), bem como o léxico cossivel para este tema entre parênteses (caneluras...). A lista das palavras é aberta - ela termina por um etc. As o:açães também se interrompem: "base hexagonal do castiçal, etc.", "suporta... etc." São fo:necidas apenas as diretrizes da descrição, pressupondo-se a participação do leitor nes'e exercício estrutural de expansão e de variação que transforma nossa leitura passiva em escritura.

22 RICARDOU, J. Le Nouvea Roman. Pa:is, Seuil, 1973. p. 112. 
Em outro caso, o narrador, mais explícito, interrompe a descrição e diz: "isso é suficiente, você pode continuar" (Projet, p. 110).

\section{Simetrias, repetiçöes, varianiles.}

O que chama a atenção, no Novo Romance, é a sofisticação das simetrias, das correspondências sobre as quais ele é construído. Podemos citar, entre tântos exemplos, Les Gommes e suas coincidèncias com um mito invertido ou parodiado de Édipo, La mise en scène e sua estrutura circular, seus quiasmas, a estrutura em 8 de Le Voyeur, etc. Isso revela que o romance de agora não nasce de uma história pré-concebida, mas de um mecanismo formal que the serve de modelo.

O que desnorteia o leitor é o jogo de repetições de mesmas cenas ou de suas variantes. Em La Jalousie, encontramos seis variantes da cena do esmagamento da centopéia, outras seis da ida de Franck à cidade, etc. A aproximação destas repetições, a sua disposição e alternância no espaço textual vão constituir as chamadas metáforas implícitas ou metáforas estruturais. A progressão dos ciúmes á meramente o produto da aproximação de diversos quadros descririvos. Estes laços metafóricos atingem o paroxismo quando as metáioras subjacentes se unem para formar uma alegoria quase aparente: "Na pressa de chegar ao fim, Franck acelera ainda mais. Os solavancos se tornam mais violentos. Ele continua entretanto a acelerar". $\left({ }^{24}\right)$ A descrição da viagem de automóvel trai, alegoricamente, 0 comportamento erótico de Franck. Observe-se, no texto em francês, a sugestão cahots (solavancos) - coit (coito).

As variações podem gerar diversas leituras.

La Prise de Constantinople (Ricardou), um mesmo cenário é descrito várias vezes $\mathrm{cum}$ pequenas variações, em que vamos perceber as duas letras-chaves da narrativa: 0 i e $\circ 0$. Um narrador descreve um minarete e a lua incidindo exatamente sobre ele produz a

24 "Dans sa hâte $d$ 'arriver au but, Franck accelère encore l'allure. Les cahots deviennent plus violents. II continue néanmoins d'accélerer". La Jalousie, p. 116.

23 "Sur le marbre, noir et terne, la petife clef se dessine en lignes claires avec la netteté d'un schéma de leçons de choses. Son anneau, plat, perfaitement circulaire, est situé à quelques centimètres seulement de la base hexagonale du bougeoir, etc., dont le corps mouluré (gorges, tores, cavets, doucines, scoties, etc.) supporte... etc." Projet... p. 12-13. 
forma de um i. Mais adiante, de uma outra perspectiva, a lua parece afastar-se obliquamente da torre. Então, palavras como lampadário, ovóide, oval que se juntam à descrição vão sugerir duas leituras: a da "Prise de Constantinople", uma narrativa de dimensão referencial a história das guerras na tomada de Constantinopla e uma narrativa literal, a "Prose de Constantinople", a própria escitura. Como diz Ricardou, não pode haver "prise sans prose", isto, não há linguagem que não produza uma ficção, bem como não pode haver "prose sans prise", isto , não há ficção sem linguagem. $\left({ }^{25}\right)$

Paralelamente à versão guerreira, temos ainda uma versão erótica, que Ricardou chama de "versão pubiana" de Constantinopla. Nesta versão, o $\mathbf{i}$ aparece como uma letra fálica e o o como uma letra vulvar. Daí a possibilidade de uma leitura licenciosa do título: "La prise du con".

O gosto pelos títulos anagramáticos é, pois, evidente no Novo Romance. La Bataille de Pharsale (Claude Simon) é menos o combate dos macedônios que os conflitos de uma "bataille de la phrase". A narrativa das guerras se intimida diante da guerra das narrativas.

\section{3."Mise en abyme", "mise en périhérie" e micro-semelhanças lexicais geradoras.}

A mise em abyme pode ser definida como uma cena microscópica, uma representação icônica que vem sobrepor-se analogicamente à cena "principal". Enquanto enunciado que se refere a outro enunciado, a mise en abyme é um termo do código metalinguístico. Esta espécie de intratextualidade ou de resumo autotextual desdobra total ou parcialmente a narrativa, tanto na sua dimensão referencial quanto na sua dimensão literal.

Ao nível referencial ou diegético, a mise en abyne age como um resumo da macro-estrutuia da fábula. A micro-história pode ser fornecida por uma gravura, um espelho, fotografias, escudos, brasões, por um filme, por um livio que aparece no interior do próprio livro. O exemplo de Le Voyeur é clássico.

Mathias, subindo as escadas de um hotel, encontra a porta de

25 RICARDOU, Lo Nouveau Romann... p. 168 
um quarto aberta, de onde observa os lençóis da cama em desalinho que, diz o texto, "refletem aspectos de luta" ou - e imediatamente a narração corrige a hipótese - "um quarto que está sendo arrumado". Numa parede, uma gravura reproduz um quario análogo, mas com uma jovem ajoelhada, à beira da cama, fazendo sua prece. (Le Voyeur, p. 67-68). O quadro revela então a cena que está ausente: a jovem, numa atitude de súplica, trai o crime de Mathias (a violação de Jacqueline ou Violette).

A mise en abyme tem geralmente uma função reveladora: ela denuncia o que a história primeira quer esconder. Mas, acontece que antecipando, refletindo a priori o macro-acon'ecimento correspondente $\left({ }^{26}\right)$, a cena microscópica tem uma função profética. Neste caso é ela própria quem gera a ficção. Se a mise en abyme esclarece a ficção é porque, em certos casos, ela tem a função de matriz geradora, concebendo a ficção à suã própria imagem. A mise en abyme tornase, afinal, uma "macro-história" por um processo de "mise en périphérie" $\left.{ }^{\prime \prime}{ }^{27}\right)$, funcionando como um modelo, um jogo de diretrizes, um simulacro da ficção. Assim, a mise en abyme liminar não seria apenas prospectiva, całafórica, mas retroprospectiva, isto é, um pivô entre um "déjà" e um "pas encore" $\left({ }^{28}\right)$

Numa dimensão literal, a mise en abyme reflete o fazer do texto. Assim, em Projeło, é uma reunião política que lembra o funcionamento do romance:

O tema da lição do dia parece ser a "cor vermelha', encarada como solução radical do irredutível antagonismo entre o negro e o branco. Cada uma das três vozes são destinadas, agora, a uma das maiores ações libertadoras se referindo ao vermelho: a violação, 0 incêndio e 0 assassinato". $\left({ }^{29}\right)$

26 Ex'ste também refletindo a história acontecida, a mise en abyme retrospectiva, terminal ou "coda", mais rara. Ver DALLENBACH, Lucien, Intertexte et autotexte. Poétique (27): 282, 1976.

27 RICARDOU, Le Nouveau Romann... p. 53-54

28 DALLENBACH... p. 286.

29 "Le thème de la leçon du jour parait être "la couleur rouge", envisagée comme solution radicale à l'irréductible antagonisme entre le noir et le blanc. Les trois voix sont chacune aftribuées, à présent, à l'une des actions libératrices majeures se rapportant au rouge: le viol, l'incendie, le meurtre". Projet... p. 38. 
Isto é: a solução do conflito entre a tinta (o negro) e o papel (o branco) é a revolução da escritura (o vermelho). O lexema rouge, desdobrando-se em anagramas que estrelam o espaço textual de Projeto (roux, rue, orgue, organe, orgasme, jeu, bouge, etc.), age como um produtor de ficção, geiando as cenas erótico-sádicas de violação, incêndio e morte.

A mise en abyme põe em cheque toda e qualquer ordem cro.. nológica, pois "incapable de dire la même chose en mâme temps qu'elle, l'analogon de la fiction, en le disant ailleurs, le dit à con'retemps et sabote par là même l'avancée successive du récit". $\left({ }^{30}\right)$.

Não sem paradoxo, a mise en abyme opera simultaneamente a fragmentação e a unificação do texto. Ao multiplicar as micro-histórıas, ela realiza uma dispersão metonímica que contesta a unidade. Mas, é também um fator de unificação na medida em que reúne os fragmentos metaforicamente, ao nível temático.

Enquanto um "embrayeur d'isotopies", a mise en abyme dota o texło de uma estrutura sólida, fazendo com que a obra dialogue consigo mesmo num mecanismo de autoleituia de auto-interpretação.

Como vimos no último exemplo de Projeto, micro-semelhanģas lexicais geram galáxias de ficção, da mesma forma que a mise enl abyme é matriz da diegese e da escritura a um nível macro-analógico.

Por micro-semelhanças lexicais geradoras entende-se: a repetição insistente ou refrāo de um mesmo vocábulo no texto todo (a palavra. oito, por exemplo, em Le Voyeur); o vocábulo polissêmico ("... elle est vive. Vive. Elle était. Vive. Vivante. Brulée vive", ainda Le Voyeur, p. 120); a homonimia (o título La Jalousie é um exemplo típico), o trocadilho (às vezes licencioso como o lit-bite-noeud/libidineux de la $\mathrm{Ba}$ taille de Pharsale, gerando uma série de cenas eróticas), a rima (violetre, fillette, cordellete, movette, cigarrette, bigkclette, de Le Voyeur), etc.

Assim, vemos a poesia invadir o domínio da narrativa. Sem negar a metonímia, o desenvolvimento linear, o Novo Romance é sobretudo construído sobre a matáfora que agride constantemente o processo de contigüidade. A rima, re!ativamente desdenhada na 
poesia contemporânea, reencontra seu campo de ação na moderna prosa romanesca.

\section{IV}

\section{NARCISISMO LITERARIO, GRATUIDADE, ENQUETE, EROTISMO}

Contestando a dimensão referencial do romance clássico, o Novo Romance se volta para o funcionamento do próprio texto, para sua auto-representação. Este narcisismo literário reflete um certo ceiicismo em relação ao tipo de arte que exprime uma ordem reconfortante, um sentimento de plenitude, de organização. Marcado pela ambigüidade, pela falta de unidade, pela insegurança, por um mundo reificado, o romance moderno representa o caos de nossa atualidade.

O novo texto é uma atividade lúdica. Nele, as alusões ao jogo são uma constante: as personagens jogam cartas, tênis, palitos de fósforos. Mas é sobretudo no plano estrutural que o jogo se realiza. Longe de ser mera brincadeira, ele é uma forma de reação ao jugo da rзzão crítica, da educação inielectual, um modo de restabelecer a liberdade primitiva.

Parodiando o romance policial, o Novo Romance apresenta a estrutura de uma enquete, de uma investigação. Seu mundo é o da suspeita generalizada, seu procedimento é o do interrogatório, do questionamento sempre renovado.

A quantidade de cenas eróticas que o Novo Romance empresta da literatura popular tem por finalidade seduzir o leitor - tanto o ingênuo, que procura o texto de prazer, quanio o leitor que encontra - prazer no desnudamento, no strip-tease dos mecanismos da escritura. Assim, o ato de ler e de escrever torna-se literalmente uma atividade erótica.

\section{V \\ PROJETO PARA UMA REVOLUÇÃo}

De uma perspectiva sociológica, pode-se perfeitamente reconhecer no Novo Romance a denúncia de todo um sistema. Mas é recusando o engajamento que o seu texto foge ao maniqueísmo do bem e do mal, na busca das ambigüidades da lógica relativista. A função 
da arte não é ilustrar valores e significados já existentes, mas trazer ao mundo novos significados, como enfatiza Robbe-Grillet na esteira de um pensamento clássico.( $\left.{ }^{31}\right)$

"O engajamento é, para o escritor, a plena consciência dos problemas atuais de sua piópria linguagem".(32) "Uma obra reacionária por sua escritura não poderá jamais ser revolucionária, ainda que relate estórias de greves ou de guerra nacional". ${ }^{\left({ }^{33}\right)} E$ porianlo no seu cunho altamente crítico que reside a revolução da nova literatura.

Habituado à mistificação de tanta obra que oferece um universo estável, coerente, univoco, facilmente decodificável, o leitor passivo vê-se de repente diante de uma leitura incômoda, que o solicita. Exigindo intensa participação no traba!ho de decifração do texto, o frocesso de leitura se assimila ao da escrituia, onde o leitor se forna um produtor e a obra coletiva. Empreendendo um verdadeiro trabaTho de descondicionamento, o Novo Romance treina e forma novos leitores, capazes de desmascarar toda linguagem coercitiva através de uma permanente crítica das propagandas.

\section{Outubro de 1978}

31 ROBRE-GriLlet, A. Pour un Nouvesu Roman... p. 14.

32 lbid. p. 46.

33 Citado por Afonso Romano de Santana na sua introduçäo a tradução de Projoto para uma rovolução em Nova lorquo. Rio de Janeiro, Companhia Editora Americana, 1975. p. IX.

\section{REFERENCIAS BIBLIOGRAFICAS}

1. BENVENISTE, E. Problómes de linguistique gónórale. Paris, Gallimard, 1966. 356p.

2. BOTHOREL, Nicole ef alii. Les Nouveaux Romanciers. Paris, Bordas, 1976. 216 p.

3. DALLENBACH, Lucien. Intertexte et autotexte. Poétique (27): 282-296, 1976.

4. GOLDMANN, Lucien. A sociologia do romance. Rio, Paz e Terra, 1976. 224p.

5. HUTCHEON, Linda. Modes et formes du narcisisme littéraire. Pobtique (29):90-106, 1977.

6. KRISTEVA, Julia. Semiotikó; recherches pour une sémanalyse. Paris, Seuil, 1969. 380p.

7. OLLIER, Claude. La mise en sedne. Paris, Minuit, 1959. 252 p.

8. RICARDOU, Jean. L'Observatoire de Cannes. Paris, Minuit, 1961, 208 p.

9. - L prose de Constentinople. Paris, Minuit, 1965. 276 p.

10. - Problèmes du Nouveau Roman. Paris, Sevil, 1967. 208 p. 
11.

- Pour une théorie du Nouveau Roman. Paris, Seuil, 1971. 270 p.

12. Lo Ncuveau Roman. Paris, Seuil, 1973. 190 p.

13. - Nouveau problèmes du roman. Paris, Seuil, 1978. 363 p.

14. ROBBE-GRILLET, Alain. Les Gommes. Paris, Minuit, 1953. 264 p.

15. - Le Voyeur. Paris, Minuit, 1955. 256 p.

16. - La Jalousie. Paris, Minuit, 1957. 224 p.

17. —- Dans le labyrinthe. Paris, Minuit, 1959. 224 p.

18. - - Pour un nouveau roman. Paris, Gallimard, 1963. 195 p.

19. - La maison de rendez-vous. Paris, Minuit, 1965. 220 p.

20. - Projet pour une révolution à New York. Paris, Minuit, 1970. 216 p.

21. -_- Topologie d'une cité fantôme. Paris, Minuit, 1976.

22. - - Souvenirs du triangle d'or. Paris, Minuit, 1978. 237 p.

23. ROBBE-GRILLET, Aiain. Un régicide. Paris, Minuit, 1978. 227 p. Primeiro romance do autor, terminado em 1949 e só agora publicado, com pequenas correçōes.

24. __- Projeto para uma revolução em Nova lorque. Rio, Companhia Editora Americana, 1975. $144 \mathrm{p}$.

25. SARRAUTE, Nathalie. L'ère du soupçon. Paris, Gallimard, 1956. 156 p.

26. SIMON, Claude. La Bataille de Phersale. Paris, Minuit, 1969. 272 p.

27. - - Tryptique. Paris, Minuit, 1973. 226 p.

\section{RESUMO}

A autora mostra as características e a evolução do Novo Romance francês até as últimas tendências do chamado "Neo-Novo Romance". O Novo Romance denuncia todo um sistema monológico, pois sua decodificação exige uma participação ativa do leifor quando, por exemplo, sujeito do enunciado coincide com sujeito da enunciação e destinatário. Neste processo de escritura-leitura, o Novo Romance é uma atividade essencialmente crítica: ele treina e forma leitores capazes de reconhecer todos os asnectos do discurso autoritário.

\section{RESUME}

L'auteur présente les caractéristiques ef l'évolution du Nouveau Roman Français qui aboutit au "Néo-Nouveau Roman". Le Nouveau Roman dénonce tout un système monologique car son décodage exige une participation active de al part du lecteur lorsque, par ex-riple. 'e sujet de l'énoncé coincide avec le sujet de l'énonciation et le destinataire. Dans ce processus d'écriture-lecture, le Nouveau Roman est une activité essentiellement critique: il entraine et forme des lecteurs capables de reconnaitré tous les aspects du discours autoritaire. 